\title{
Soft and effective detoxification of a VX simulant in a nylon 3D printed basic flow reactor
}

\author{
Sergui Mansour, ${ }^{a}$ Antonin Delaune, ${ }^{a}$ Maxime Manneveau, ${ }^{a}$ Baptiste Picard, ${ }^{a}$ Amélie Claudel, \\ Cécile Vallières, ${ }^{b}$ Léa Sigot, ${ }^{b}$ Pierre-Yves Renard, ${ }^{a}$ and Julien Legros* ${ }^{a}$
}

The neutralisation of a simulant of the chemical warfare agent $\mathrm{VX}$ (PhX) occurs selectively with lithium ethanolate under classic flow conditions but with moderate reproducibility. Transposed in a nylon custom printed flow reactor, simply feeded with an ethanolic solution of $\mathrm{PhX}$, the formation of EtOLi and the neutralisation are performed in a single operation. Robustness and recyclability of the device is also demonstrated.

\section{Introduction}

The synthesis and holding of chemical warfare agents (CWA) are strictly controlled and their use is limited to protection and peaceful research. Unfortunately, despite the international guardrails of the Chemical Weapon Convention the threat of CWA is still ongoing: multiple cases of their use were reported during the Syrian war, and two murder attempts were perpetrated during the past years with organophosphorous nerve agents (OPNA) in Kuala Lumpur (VX agent) and in Salisbury (non-declared nerve agent from the so-called "Novichok" series). ${ }^{1-3}$ OPNA are extremely toxic and the most harmful VX causes rapid death by irreversibly inhibiting a key enzyme for nerve impulse termination : acetylcholinesterase (AChE). ${ }^{4,5}$ Whereas hydrolysis of $V$-series OPNA could look as an ideal detoxification path, this is a deceptively simple way for several reasons. ${ }^{6-8}$ First, the hydrolysis has to selectively take place onto the P-S bond to afford phosphonic acid 1, since POR cleavage will afford the still toxic and stable desethyl compound 2 (Fig. 1) ${ }^{9}$ second, V-series OPNA display an hydrophobic character, with obvious problems of mass transfer under such heterogeneous conditions. Finally, if water is often presented as a green solvent, performing reactions with toxic compounds in aqueous media will inevitably release polluted water that will have to be further decontaminated to avoid environmental and health issues.

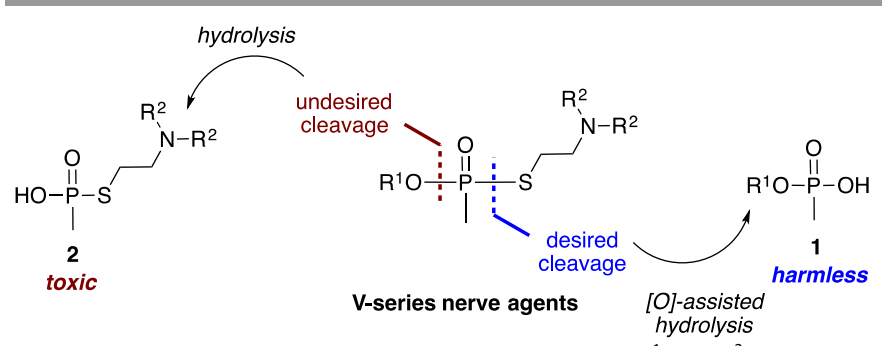

Fig. 1. General decomposition paths of $\mathrm{V}_{2}$-series OPNA: $\mathrm{VX}\left(\mathrm{R}^{1}=\mathrm{Et}, \mathrm{R}^{2}=i-\mathrm{Pr}\right), \mathrm{R}-\mathrm{VX}$ Fig. 1. General decomposition paths of $\mathrm{V}^{2}$-series
$\left(\mathrm{R}^{2}=i-\mathrm{Bu}, \mathrm{R}^{2}=\mathrm{Et}\right)$ and $\mathrm{C}-\mathrm{VX}\left(\mathrm{R}^{1}=n-\mathrm{Bu}, \mathrm{R}^{2}=\mathrm{Et}\right)$

In order to ensure the selective P-S cleavage, the hydrolysis can be oriented by first forming in situ an oxidized-sulfur leaving group. This oxidation-triggered decontamination is generally performed by mean of an excess of aqueous acidic Oxone solution $\left(2 \mathrm{KHSO}_{5} \cdot \mathrm{KHSO}_{4} \cdot \mathrm{K}_{2} \mathrm{SO}_{4}\right.$ ) under batch conditions as demonstrated by Yang. ${ }^{10}$ In the search for flexible and sustainable methods for on-site neutralisation of chemical warfare agents, continuous flow systems offer the possibility to handle highly toxic and corrosive compounds without exposing the operator. ${ }^{11-16}$ Moreover they offer a high flexibility on the volumes from lab scale to production. ${ }^{17-21}$ In this connection, we recently showed that the oxidative decontamination of OPNA of the V-series could be performed with an enriched aqueous solution of Oxone in a flow device. ${ }^{22}$ However, the development of a method that would allow direct solvolytic detoxification of $\mathrm{V}$-series agents, under mild and oxidant-free conditions, would have a real impact. ${ }^{23}$

For this purpose, functionalized polymers as detoxifying materials represents a valuable assistance. Thus, Hatton described the fully selective hydrolysis of $1 \mu \mathrm{L}$ of $\mathrm{VX}$ into the harmless ethyl methylphosphonic acid (EMPA) in the presence of the nucleophilic polymer PVAm-APy in $\mathrm{H}_{2} \mathrm{O}$ /DMSO (Fig. 2). ${ }^{24}$ On another hand, Columbus and Zafrani reported the use of a commercial resin Amberlite IRA $900 \mathrm{~F}^{-}$(a copolymer substituted with benzyl trimethyl ammonium fluoride) for the hydrolytic degradation of VX (Fig. 2). ${ }^{25}$ This neutralisation proceeds in two steps: first, the nucleophilic fluoride ion substitutes the aminothiolate group of $\mathrm{VX}$, to form a reactive intermediate "G-analogue" compound; in the second step the new P-F bound is broken with the introduction of the nucleophilic solvent to afford the desired EMPA 1a within $4 \mathrm{~h}$ in water. 


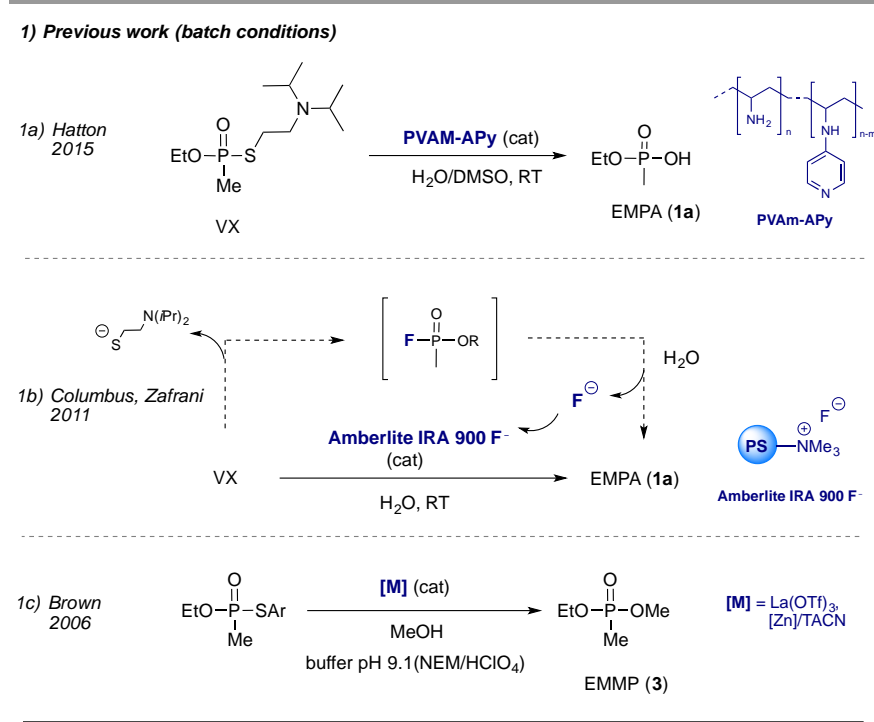

2) This work (flow conditions)

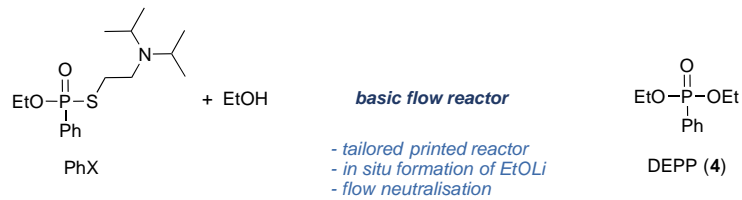

Fig 2. 1) Previous reports on solvolysis of $V X$ and phophonothioate under batch conditions: $1 \mathrm{a}$,b) Hydrolysis of VX assisted by functionalized polymers; ${ }^{24,25} 1 \mathrm{c}$ ) Metalcatalysed methanolysis of $S$-aryl-O-ethyl phosphonothioates. ${ }^{26}$ 2) This work on ethanolysis of the $\mathrm{V}$-simulant $\mathrm{PhX}$ in a flow system. PVAm-APy = polyvinylamine modified by 4-aminopyridine; PS = polystyrene; NEM = N-ethylmorpholine; TACN triazacyclononane.

Whereas hydrolysis is the most common solvolysis path used to decompose compounds, ethanolysis also presents much interest: ethanol is a biobased solvent with a good ability for solubilising organic molecules with positive consequences on mass transfer and scale-up compared to biphasic aqueous conditions. Moreover, alcoholic solutions allow final pyrolytic treatment, the terminal irreversible step in the destruction of CWA. Thus, Brown reported the methanolysis of $O$-ethyl $O$ phenyl methylphosphonates as G-series mimics with the assistance of a metal catalysis ([La], [Zn]; Fig. 2). ${ }^{26}$ This strategy was latter extended to $S$-aryl phosphonothioates, a limited Vseries agent simulant. ${ }^{27}$ Importantly, this reaction was performed in a perchlorate-based buffer solution $(N$ ethylmorpholine $\left./ \mathrm{HClO}_{4}, 4: 1\right)$, which questions the possible formation of a transient $S$-oxidized intermediate to assist solvolysis into EMMP $3 .^{28}$ Actually, the legislation on the handling of CWA being very restrictive and limited to dedicated military premises, decontamination studies are generally performed on simulants. ${ }^{29}$ Relevant simulants must then finely mimic reactivity of the original compound but with acceptable toxicity to work in an academic laboratory. Among all VX simulants, the $\mathrm{PhX}$, described in 2002 by Renard and Mioskowski, ${ }^{30}$ exhibits the closest reactivity to that of the original agent VX (Fig. 2) : arylphosphonothioate vs. methylphosphonothioate with accurate S-aminoalkyl and O-Et side chains as leaving groups. ${ }^{22}$ Herein, we now report the mild and direct neutralisation of an accurate simulant of $\mathrm{V}$-series agents (PhX) by simply feeding a basic 3D printed flow reactor with ethanol (Fig. 2).

\section{Experimental section}

\section{General information}

All reagents were purchased from Sigma Aldrich and used as provided; solvents were purchased from VWR and used without further purification. All fluidic tubing, connections, adapters were manufactured by IDEX Health and Science. Syringe pumps were manufactured by Harvard apparatus (Pump 11 Elite and PHD/ULTRA) with SGE glass and Air Tite plastic syringe.

All reactions were conducted at room temperature $\left(23^{\circ} \mathrm{C}\right)$ except if noted otherwise, with no particular precautions with regard to residual moisture and air. $\mathrm{PhX}$ was synthesized according to the literature; ${ }^{30}$ however due to the acute toxicity of CWA simulants, reactions were carried out in a very wellventilated fume hood. The solution of EtOLi in EtOH $(0.3 \mathrm{M})$ was prepared by diluting $1.2 \mathrm{~mL}$ of $n$-Butyl lithium $(2.5 \mathrm{M}$ in hexane) in $8.8 \mathrm{~mL}$ of anhydrous ethanol.

Typical procedure for the $\mathrm{PhX}$ neutralization with lithium ethanolate in a basic flow reactor

A flow system was set up with the following elements: two syringe pumps, each equipped with a $5-\mathrm{mL}$ syringe, connected to a PEEK T-shaped mixer and a $200 \mu \mathrm{L}$ PFA tubular microreactor $(\mathrm{L}=10 \mathrm{~cm}, I D=1.58 \mathrm{~mm}, O D=3.18 \mathrm{~mm})$. $A$ solution of EtOLi in EtOH $(0.3 \mathrm{M})$ in a syringe was injected in the flow system in a first inlet (flow rate $Q_{1}=8.85 \mu$ l. $\mathrm{min}^{-1}$ ). A solution of $\mathrm{PhX}(0.06 \mathrm{mmol}, 20 \mathrm{mg})$ in ethanol $0.2 \mathrm{~mL}$ of EtOH $(0.3 \mathrm{M})$ in a syringe was injected in the flow system in a second inlet (flow rate $\mathrm{Q}_{2}=2.95 \mu \mathrm{l} \cdot \mathrm{min}^{-1}$ ). The outlet of the reactor was collected in a flask containing ethanol charged with anhydrous $\mathrm{HCl}$ to quench the excess of EtOLi. The crude mixture was then analysed by ${ }^{31}$ P NMR.§

Typical procedure for the manufacture of the nylon custom printed reactor and chemical modification

The flow reactor was designed through CAD with SolidWorks ${ }^{\circledR}$ software (see ESI for further details) and printed in an extrusion-based 3D printer Stream 30 Ultra Volumic ${ }^{\circ}$. The internal surface of the printed nylon 3D reactor was hydrolysed by successive introduction at a constant flow rate of $667 \mu \mathrm{l} . \mathrm{min}^{-1}$ of $\mathrm{HCl}\left(0.5 \mathrm{M}\right.$ in $\left.\mathrm{H}_{2} \mathrm{O}, 15 \mathrm{~min}\right)$, then washed with $\mathrm{H}_{2} \mathrm{O}(60 \mathrm{~min})$ and finally treated with potassium phosphate buffer ( $\mathrm{pH} 8.0,0.1 \mathrm{M}$ in $\mathrm{H}_{2} \mathrm{O}, 60 \mathrm{~min}$ ). Finally, the modified reactor was dried under vacuum for $10 \mathrm{~h}$ at room temperature. Then, the reactor was filled with a $n$-BuLi solution (2.5 $\mathrm{M}$ in hexane) and kept for $3 \mathrm{~h}$. The excess of $n$ BuLi was removed by washing the reactor with heptane and dried under vacuum for $2 \mathrm{~h}$ at room temperature.

Typical procedure for the neutralisation of $\mathrm{PhX}$ in the 3D printed basic flow reactor

A flow system was set up with the following elements: one syringe pumps was equipped with a $20-\mathrm{mL}$ syringe and 
connected to a PuriFlash F0012 cartridge filled with 3 custom printed reactors, vide supra. The syringe was filled with a solution of $\mathrm{PhX}(1.5 \mathrm{mmol}, 500 \mathrm{mg})$ in EtOH $(20 \mathrm{~mL})$. The PhX solution was introduced into the modified nylon printed reactor (flow rate $Q=50 \mu \mathrm{l} \cdot \mathrm{min}^{-1}$ ). The outlet of the reactor was collected in a flask containing ethanol charged with anhydrous $\mathrm{HCl}$ to quench the excess of EtOLi. The crude mixture was then analysed by ${ }^{31} \mathrm{P}$ NMR. $\S$

\section{Results and discussion}

Unlike the conventional flow system that are composed of (plastic or metal) tubing connected together, computer assisted design (CAD) combined to additive manufacturing (3D printing) allows to assemble microfluidic reactors with a complex geometry and sophisticated system of channels. ${ }^{31-36}$ Furthermore, it is possible to engineer the surface by grafting a specific functionality for a given reaction. ${ }^{37}$ For this purpose, polyamide-based reactors are much valuable, since such polymers can now be produced from renewable feedstocks, ${ }^{38-}$ ${ }^{40}$ including nylon-6 and $-6,6 .{ }^{41}$ In a recent sound article, Sans reported the preparation of a 3D printed nylon-based bioreactor for transamination reactions. ${ }^{37}$ The multistep modification of nylon-6, 6 began with polyamide hydrolysis to release the $\mathrm{NH}_{2}$ groups. Based on this mechanism, we reasoned that a basic flow reactor could be obtained in a single step by treating the released $\mathrm{NH}_{2}$ moieties with $n$-BuLi to form a supported version of lithium amide $\left(\mathrm{p} K_{\mathrm{a}} \sim 35\right)$. A solution of $\mathrm{V}$-series OPNA in ethanol would then be injected into the flow system where the more acidic ethanol $\left(\mathrm{p} K_{\mathrm{a}}=16\right)$ will be deprotonated in situ to generate the nucleophilic EtOLi that will react with the OPNA.

\section{Direct flow neutralisation of $\mathrm{PhX}$ with a solution of EtOLi in EtOH}

As a preliminary experiment, we assessed the validity of our neutralisation model of PhX by EtOLi by implementing a simple flow set-up consisting of PTFE T-shaped micromixers and a 200 $\mu \mathrm{L}$ PFA tubular microreactor. A solution of $\mathrm{PhX}$ in ethanol was introduced in the first inlet and reacted with a solution of EtOLi in EtOH (molar and volumetric ratio PhX/EtOLi 1:3) coming from the second inlet to afford the innocuous diethyl phenylphosphonate (DEPP, 4), as shown by comparison on NMR analyses with authentic sample of this phosphonate.§ The reactor outlet was then collected in a solution containing anhydrous $\mathrm{HCl}$ in $\mathrm{EtOH}$. Modification of the flow rate allowed fine kinetic measurement according to $t^{R}=$ (reactor volume)/(flow rate) where $t^{R}$ is the residence time in the microflow reactor, ie the reaction time (Fig. 3 ). (a)

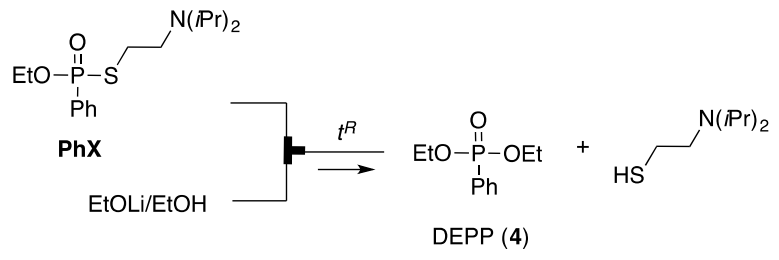

(b)

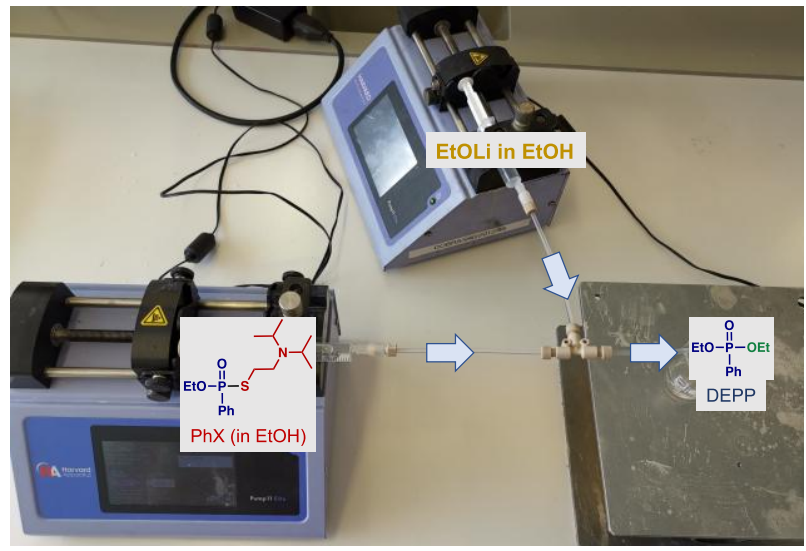

(c)

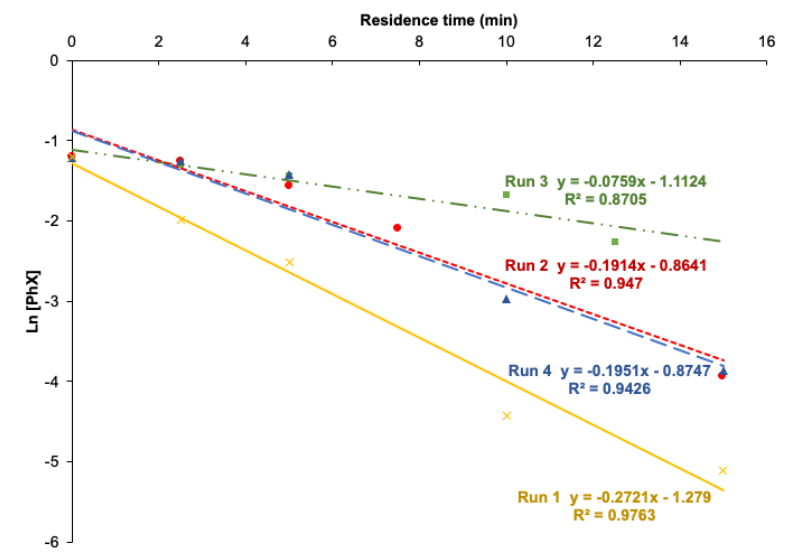

Fig. 3 (a) Set-up for the flow neutralization of $\mathrm{PhX}$ with EtOLi under liquid conditions. (b) Picture of the set-up. (c) kinetic measurement of the reaction.

Delightfully, $\mathrm{PhX}$ was fully converted into the target phosphonate product DEPP (4) within only 17 min with a first order rate constant $k_{\text {obs }}=0.27 \mathrm{~min}^{-1}$ (Fig. 3 and Table 1, Run 1).

Table 1. Reaction rate constants $k_{\mathrm{obs}}$ and the coefficient of determination $\left(\mathrm{R}^{2}\right)$ for 4 runs R1-4 of the flow neutralisation of $\mathrm{PhX}$ with a prepared solution of EtOLi. ${ }^{a}$

\begin{tabular}{lllll} 
& \multicolumn{4}{c}{ Run } \\
\cline { 2 - 5 } & 1 & 2 & 3 & 4 \\
\hline$k_{\text {obs }}\left(\mathrm{min}^{-1}\right)$ & 0.27 & 0.19 & 0.08 & 0.20 \\
$\mathrm{R}^{2}$ & 0.976 & 0.947 & 0.871 & 0.943 \\
& & & \\
${ }^{a}$ All experiments were performed with $[\mathrm{PhX}]_{0}=0.3 \mathrm{M}$.
\end{tabular}

In order to assess the reproducibility of the system, three further kinetic measurements were performed under the same conditions, each experiment being conducted with a freshly prepared solution of EtOLi. Disappointingly, the observed standard deviation was significant with a $25-70 \%$ drop for run 2,3 and $4\left(k_{\text {obs }}=0.19,0.08\right.$ and $0.20 \mathrm{~min}^{-1}$ respectively $)$ with regard to run 1 , and a coefficient $R^{2}$ that gives no confidence 
on reaction rates. One possible explanation for these scattering of kinetics might come from the decomposition of lithium ethoxide that is very moisture sensitive and cannot be kept for an extended period of time. Thus, experiments measuring the decomposition of EtOLi over time have been conducted: [EtOLi] dropped to $89 \%$ after $2 \mathrm{~h}$ and $73 \%$ after $5 \mathrm{~h}$ (see ESI for details). However, this phenomenon cannot account alone for the kinetic scattering and the linear regime of the flow system, with a poor mixing in a simple T-shaped mixer, is also in question. Therefore, these experiments under fully liquid conditions show that the neutralisation of a $\mathrm{V}$-series agent through direct nucleophilic substitution with an alcoholate in a flow device is fully selective, but the poor stability of EtOLi solution and a mass transfer governed by diffusion under linear regime constitute a drawback for a secured detoxification. $\neq$

\section{Flow neutralisation in a basic 3D-printed reactor}

Therefore, generating directly lithium ethanolate in the flow system by means of basic reactor would be a safe and efficient alternative. For this, we developed a tailored, 3D-printed flow reactor bearing basic moieties. The reactor was first designed through computer assisted design (CAD) with SolidWorks ${ }^{\circledR}$ software (Fig. 4a). For obvious practical reasons, microchip systems are often designed with a single tubular channel However, in our case we anticipated that, once the microreactor will be printed with nylon, the treatment with aqueous $\mathrm{HCl}$ (vide supra) will affect the reactor integrity with partial collapse of the internal walls, and likely clogging of the flow device. Thus, we chose to design a microreactor composed of several parts with multiple channels separated from each other. Moreover, such a design will increase the internal reactive surface and area available. Such a conception shall allow printing, internal surface modification and finally proper operationality of the system under flow conditions even if undesired clogging of a few channels occurred. The microreactor is designed as $2 \times 2 \mathrm{~cm}$ (length $\times$ diameter) cylinders, which contain 38 channels with a diameter of 1.5 $\mathrm{mm}$ with a total volume $\mathrm{V}=1.34 \mathrm{~mL}$. An upper hollow part $(\mathrm{V}=$ $0.64 \mathrm{~mL}$ ) was also designed to act as a spacer which result in a volume of $5.94 \mathrm{~mL}$ and a contact surface with the nylon of $166.55 \mathrm{~cm}^{2}$, in order to pack several reactors together in a cylindrical device with a total volume capacity around $10 \mathrm{~mL}$, and allowing to replace them easily if required (Fig 4a,c).

The designed microreactor was then successfully printed with nylon-6,6 Taulman 645 (Fig 4b). Its internal surface was hydrolysed, as previously described, to release amino functions ${ }^{37}$ and further treatment of the inner channels with a solution of $n$-BuLi (1.6 $\mathrm{M}$ in hexanes) generated the corresponding lithium amides. The efficacy of the printed microfluidic reactors was determined on a cartridge filled with 3 consecutive reactors and fed with a flow of ethanol (Fig 4d). The generated lithium ethoxide (in ethanol) was then collected at the outlet and titrated in the presence of phenolphthalein. The obtained results revealed that $0.5 \mathrm{mmol}$ of EtOLi per $\mathrm{mL}$ of reactor (or $17.29 \mu \mathrm{mol} . \mathrm{cm}^{-2}$ ) were formed. In order to determine the recyclability of this material, the reactor was regenerated with $n$-BuLi and titrated as above for two further cycles. Results showed [EtOLi] $=0.49 \pm 0.05 \mathrm{mmol} / \mathrm{mL}$ of reactor for the three measurements. Therefore, the system composed of a cartridge filled with 3 consecutive reactors can generate ca. $3 \mathrm{mmol}$ of EtOLi which is shown to be able to neutralize at least $500 \mathrm{mg}$ of $\mathrm{PhX}$ (by considering a ratio $\mathrm{PhX} / \mathrm{EtOLi}=1: 2$, in order to ensure a full neutralization). Interestingly, whereas lithium bases (lithium amides or even alcoholates) are sensitive to moisture and must be kept with care, we experienced that these lithium basic cartridges can be kept for at least one month with no particular precautions without any loss in activity their effectiveness.

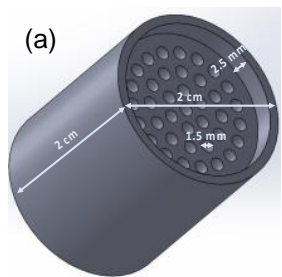

(d)

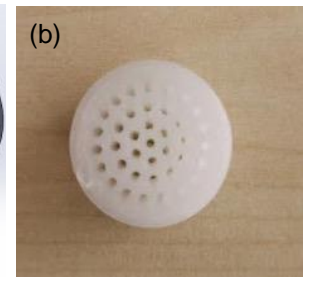

EtOH EtOLi
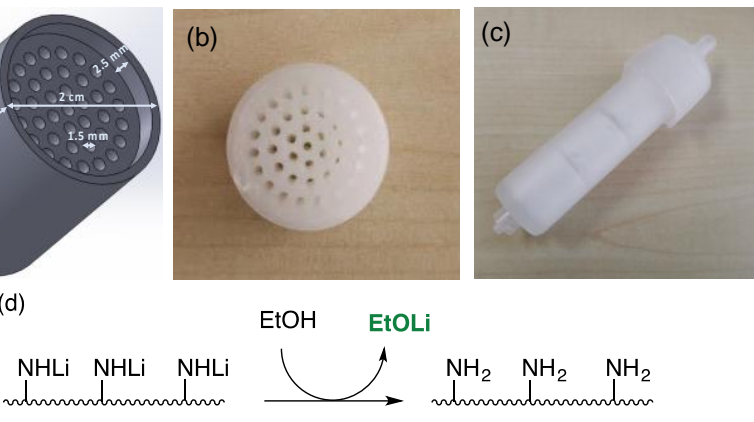

nylon modified

Fig. 4 (a) CAD of the microreactor. (b) picture of the 3D printed microreactor. (c) Cartridge filled with 3 reactors. (d) Chemically modified reactor internal surface for the formation of lithium ethanolate.

Finally, the effectiveness of the microreactor for the flow neutralisation of PhX was assessed. A syringe was thus filled with an alcoholic solution of $\mathrm{PhX}(0.03 \mathrm{M})$ and passed through the $3 D$ printed microreactor at a flow rate $Q=0.05 \mathrm{~mL} \cdot \mathrm{min}^{-1}$ corresponding thus to $t^{R}=2 \mathrm{~h}$ in the reactor, the outlet being collected in a solution containing anhydrous $\mathrm{HCl}$ in $\mathrm{EtOH}$ (Fig 5a). A ${ }^{31} \mathrm{P} N M R$ analysis of this solution showed a full and selective neutralization into harmless DEPP 4 (Fig 5b). 1 This long reaction time suggests that the main mass transfer is governed by diffusion in this reactor.

Washing the used reactor with ethanol followed by drying and treatment with $n$-BuLi afforded a fully reactivated basic reactor that was reused with complete keeping of its detoxification ability for $\mathrm{PhX}$. This recyclability was also successfully assessed in a further third run with no degradation of the selectivity for DEPP. 


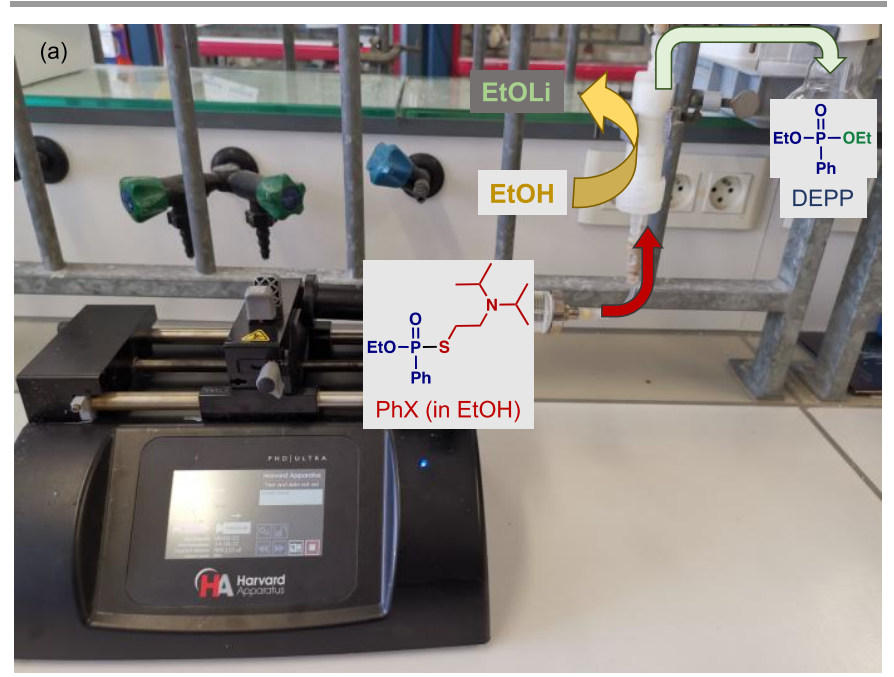

(b)
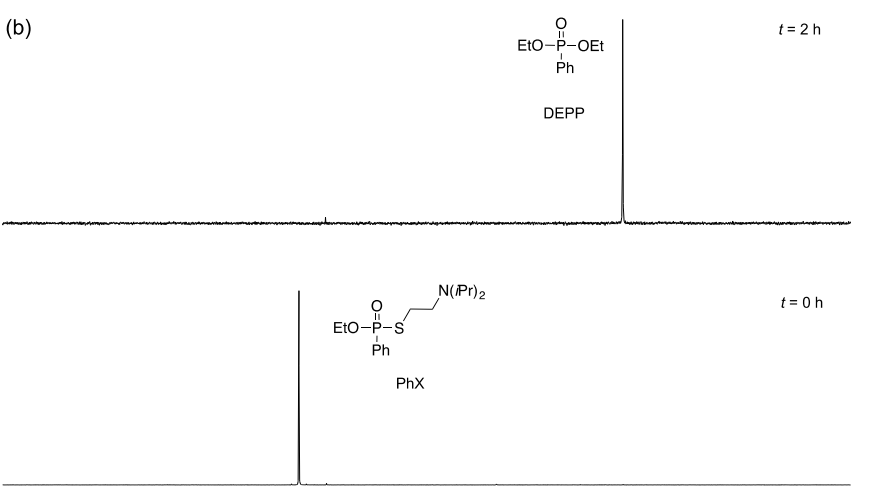

${ }^{70}$
Fig. 5. (a) Flow neutralisation of $\mathrm{PhX}$ in the basic
3D-printed reactor. (b) monitoring of $\mathrm{PhX}$ after $2 \mathrm{~h}$.

In conclusion, we have developed a flow system for the selective neutralisation of a $\mathrm{V}$-series simulant $(\mathrm{PhX})$ under mild and oxidant-free conditions with ethanolate as nucleophilic scavenger. Whereas it is possible to detoxify $\mathrm{PhX}$ with a freshly prepared EtOLi/EtOH solution, this methods lacks reliability due to sensitivity of the reagent and mass transfer issues. In contrast, generating EtOLi in situ from ethanol in a dedicated neutralisation flow system is an efficient way to decompose $\mathrm{PhX}$ into the corresponding harmless DEPP ester. For this, we designed a custom printed basic reactor made from modified nylon. Feeding this reactor with a solution of $\mathrm{PhX}$ in ethanol afforded full neutralisation of the nerve agent. Interestingly, these basic reactors can be kept with no particular precautions without any loss of activity, and were recycled at least 3 times. Interestingly, flow systems offer the possibility of upscaling processes by numbering up the reactors in the same device. ${ }^{42-}$ 44

\section{Conflicts of interest}

There are no conflicts to declare.

\section{Acknowledgements}

$\mathrm{JL}$ and SM are grateful to La Fondation Dassault Systèmes for a grant in the frame of the project 3DECON. The authors gratefully acknowledge the European France-(Manche)-England cross-border cooperation program INTERREG V A "LABFACT" and "SMARTT", cofinanced by ERDF, for financial support. 3D Solution company is thanked for its kind assistance in 3D printing. The authors from COBRA also thank the University of Rouen Normandy, INSA Rouen Normandy, the Centre National de la Recherche Scientifique (CNRS), European Regional Development Fund (ERDF), Labex SynOrg (ANR-11-LABX-0029), Carnot Institute 12C, the graduate school for research XL-Chem (ANR-18-EURE-0020 XL CHEM), and Région Normandie for support.

\section{Notes and references}

$\S^{31} \mathrm{P} N M R$ analyses were performed in $\mathrm{CDCl}_{3}$ with a coaxial inert containing $\mathrm{PPh}_{3}$ calibrated at $\delta=5 \mathrm{ppm} . \delta(\mathrm{PhX})=45.4 \mathrm{ppm}$, $\delta($ DEPP $)=19.8 \mathrm{ppm}$.

¥ Solvolysis with pure ethanol failed and $\mathrm{PhX}$ was recovered unchanged even after several hours.

I A blank experiment with unmodified nylon: PhX did not react and was recovered unchanged.

1 D. Hafemeister, in Nuclear Proliferation and Terrorism in the Post-9/11 World, Springer International Publishing, Cham, 2016, pp. 337-351.

2 M. Peplow, Chem. Eng. News, 2018, 96, 3.

3 H. John, M. J. van der Schans, M. Koller, H. E. T. Spruit, F. Worek, H. Thiermann and D. Noort, Forensic Toxicol., 2018, 36, 6171.

4 G. Mercey, T. Verdelet, J. Renou, M. Kliachyna, R. Baati, F. Nachon, L. Jean and P.-Y. Renard, Acc. Chem. Res., 2012, 45, 756766.

5 P. Masson and F. Nachon, J. Neurochem., 2017, 142, 2640.

6 Y. J. Jang, K. Kim, O. G. Tsay, D. A. Atwood and D. G. Churchill, Chem. Rev., 2015, 115, PR1-PR76.

7 Y.-C. Yang, Acc. Chem. Res., 1999, 32, 109-115.

8 T. Islamoglu, Z. Chen, M. C. Wasson, C. T. Buru, K. O. Kirlikovali, U. Afrin, M. R. Mian and O. K. Farha, Chem. Rev., 2020, 120, 8130-8160.

9 C. Wilson, N. J. Cooper, M. E. Briggs, A. I. Cooper and D. J. Adams, Org. Biomol. Chem., 2018, 16, 9285-9291.

10 Y. C. Yang, L. L. Szafraniec, W. T. Beaudry and D. K. Rohrbaugh, J. Am. Chem. Soc., 1990, 112, 6621-6627.

11 M. Movsisyan, E. I. P. Delbeke, J. K. E. T. Berton, C. Battilocchio, S. V. Ley and C. V. Stevens, Chem. Soc. Rev., 2016, 45, 4892-4928.

12 D. Dallinger, B. Gutmann and C. O. Kappe, Acc. Chem. Res., 2020, 53, 1330-1341.

13 L. Suhadolnik, D. Lašič Jurković, B. Likozar, M. Bele, S. Drev and M. Čeh, Appl. Catal. B Environ., 2019, 257, 117894.

14 L. Suhadolnik, A. Pohar, B. Likozar and M. Čeh, Chem. Eng. J., 2016, 303, 292-301.

15 L. Suhadolnik, A. Pohar, U. Novak, B. Likozar, A. Mihelič and M. Čeh, J. Ind. Eng. Chem., 2019, 72, 178-188.

16 B. M. Sharma, S.-J. Yim, A. Nikam, G.-N. Ahn and D.-P. Kim, React. Chem. Eng., 2021, 6, 1454-1461.

17 D. Webb and T. F. Jamison, Chem Sci, 2010, 1, 675-680. 
18 K. S. Elvira, X. C. i Solvas, R. C. R. Wootton and A. J.

deMello, Nat. Chem., 2013, 5, 905-915.

19 M. B. Plutschack, B. Pieber, K. Gilmore and P. H.

Seeberger, Chem. Rev., 2017, 117, 11796-11893.

20 R. Gérardy, N. Emmanuel, T. Toupy, V.-E. Kassin, N. N.

Tshibalonza, M. Schmitz and J.-C. M. Monbaliu, Eur. J. Org. Chem., 2018, 2018, 2301-2351.

21 C. Wiles and P. Watts, Green Chem., 2013, 16, 55-62.

22 A. Delaune, S. Mansour, B. Picard, P. Carrasqueira, I.

Chataigner, L. Jean, P.-Y. Renard, J.-C. M. Monbaliu and J. Legros,

Green Chem., 2021, 23, 2925-2930.

23 J. E. Forman and C. M. Timperley, Curr. Opin. Green

Sustain. Chem., 2019, 15, 103-114.

24 L. Bromberg, W. R. Creasy, D. J. McGarvey, E. Wilusz and

T. A. Hatton, ACS Appl. Mater. Interfaces, 2015, 7, 22001-22011.

25 D. Marciano, M. Goldvaser, I. Columbus and Y. Zafrani, J.

Org. Chem., 2011, 76, 8549-8553.

26 R. E. Lewis, A. A. Neverov and R. S. Brown, Org. Biomol. Chem., 2005, 3, 4082-4088.

27 S. A. Melnychuk, A. A. Neverov and R. S. Brown, Angew. Chem. Int. Ed., 2006, 45, 1767-1770.

28 L. Y. Kuo, A. Bennett and Q. Miao, Inorg. Chem., 2017, 56, 10013-10020.

29 B. Picard, I. Chataigner, J. Maddaluno and J. Legros, Org. Biomol. Chem., 2019, 17, 6528-6537.

30 P.-Y. Renard, H. Schwebel, P. Vayron, L. Josien, A. Valleix and C. Mioskowski, Chem. - Eur. J., 2002, 8, 2910-2916.

31 M. J. Harding, S. Brady, H. O'Connor, R. Lopez-Rodriguez, M. D. Edwards, S. Tracy, D. Dowling, G. Gibson, K. P. Girard and S. Ferguson, React. Chem. Eng., , DOI:10.1039/C9RE00408D.

32 F. Menzel, T. Klein, T. Ziegler and J. M. Neumaier, React. Chem. Eng., 2020, 5, 1300-1310.

33 M. C. Maier, A. Valotta, K. Hiebler, S. Soritz, K. Gavric, B. Grabner and H. Gruber-Woelfler, Org. Process Res. Dev., 2020, 24, 2197-2207.

34 O. A. Alimi, C. A. Akinnawo, O. R. Onisuru and R. Meijboom, J. Flow Chem., 2020, 10, 517-531.

35 A. K. Au, W. Huynh, L. F. Horowitz and A. Folch, Angew. Chem. Int. Ed., 2016, 55, 3862-3881.

36 B. Gutmann, M. Köckinger, G. Glotz, T. Ciaglia, E. Slama, M. Zadravec, S. Pfanner, M. C. Maier, H. Gruber-Wölfler and C. Oliver Kappe, React. Chem. Eng., 2017, 2, 919-927.

37 E. Peris, O. Okafor, E. Kulcinskaja, R. Goodridge, S. V. Luis, E. Garcia-Verdugo, E. O'Reilly and V. Sans, Green Chem., 2017, 19, 5345-5349.

38 J. A. Lee, J. H. Ahn, I. Kim, S. Li and S. Y. Lee, ACS Sustain. Chem. Eng., 2020, 8, 5604-5614.

39 S. Kind, S. Neubauer, J. Becker, M. Yamamoto, M. Völkert, G. von Abendroth, O. Zelder and C. Wittmann, Metab. Eng., 2014, 25, 113-123.

40 H. Nakajima, P. Dijkstra and K. Loos, Polymers, 2017, 9,

523.

41 https://www.genomatica.com/wp-

content/uploads/Polyamide-intermediates-1000x526px-081921v1.png

42 A. Nagaki, K. Hirose, O. Tonomura, S. Taniguchi, T. Taga, S. Hasebe, N. Ishizuka and J. Yoshida, Org. Process Res. Dev., 2016, 20, 687-691.

43 Y. Su, K. Kuijpers, V. Hessel and T. Noël, React. Chem. Eng., 2016, 1, 73-81.

44 M. Qiu, L. Zha, Y. Song, L. Xiang and Y. Su, React. Chem.

Eng., 2019, 4, 351-361. 